\title{
A Study on Aestheticization Form of Socialist Core Values from A Three-dimensional Perspective
}

\author{
Li Tao
}

School of Marxism, Northwest University for Nationalities, Lanzhou Gansu, 730030, China

Key words: Ideology, Socialist core values, Aestheticization.

\begin{abstract}
The research on aesthetics and aestheticization form of socialist core values is an important research field of socialist core values, and an important research subject, of theoretical value and practical significance in the age. Socialist core values contain the aesthetic essence of "holding goodness and truth through beauty", namely interpreting aesthetics and aestheticization form of socialist core values from a three-dimensional (theory, individual and practice) perspective, revealing the unique function of "enlightening truth and goodness through beauty" of socialist core values and acting as the motive of aesthetic practice of ideology of socialist core values.
\end{abstract}

\section{Introduction}

In the new era, as the overall reforms and opening-up of China constantly advance, the exchange and collision of various cultural thoughts worldwide and internet communication accelerate, and a new round of shock wave exercises greater and greater influences on values of various nations in the world. The coexistence of multiple values aggravates the difficulty of mutual understanding of values in the world. To develop socialist core values, it is supposed to break away from the western discourse system and present the ideological achievements of Chinese civilization, which needs the support of Chinese traditional aesthetic culture and Marxist theory. It is advisable to create a good climate and soil for socialist core values to take root and sprout and then grow into the value guidance of the Chinese dream of great rejuvenation of the nation by carrying on Chinese outstanding traditional aesthetic culture and strengthening Chinese people's cultural confidence. This paper aims to further comprehend and seek the beauty of values and ideals of socialist core values from a three-dimensional (theory, individual and practice) perspective based on the understanding of its beauty in form, and reflect on the significance of the existence of moral values in socialist core values by considering moral values as the origin of aesthetics.

\section{Significance of Interpretation of Socialist core values from An Aesthetic Perspective}

Presently, theoretical researches on socialist core values mainly focus on the scientificity and the standardability. Scientificity researches mainly relate to understanding of ideological origin and basic principle of socialist core values; and standardability explanation is mainly to emphasize the ideological effect and ethical function of socialist core values. Both of the two aspects touch the connotation of truth and goodness of socialist core values. Besides, the interpretation of socialist core values from aesthetic perspective is in line with the explanation by president Xi Jinping. Socialist core values ought to contain aesthetic meanings. The present politics and ideological construction cannot do without aesthetic guidance. Aesthetic value and ideal are the prerequisite for the reasonable existence of socialist core values, and also the motive of putting it into practice. Truth and goodness are themselves a kind of beauty, but beautiful things do not necessarily exist in the form of truth and goodness. Hence, beauty, as a value, cannot reflect the essential needs of human unless it is higher than truth and goodness. 
Socialist core values, as a norm, reflects the significance of ethics to human; as an ideal, reflects the aesthetic characteristics of politics; as a faith, needs aesthetic education to help human internalize it. Aesthetic interpretation of socialist core values helps us to get clear about its value ideal, and avoid misunderstanding it in daily life. Since there is a certain distance between our present life and socialist core values, people often doubt whether these values belong to us or not and whether it is possible to realize it.

As far as we are concerned, aesthetic interpretation of socialist core values is enlightening or significant in three aspects, as below. Firstly, socialist core values blends moral excellence with ideal beauty, and shows the internal essence of human of self-discipline and freedom. As core values, it reflects the characteristics of ethics or morality, namely regulating people's daily life. Individual self-discipline is self-motivated, and is the acknowledgement of the subject on external norms and requirements, reflecting the decisional control of the subject. Socialist core values is extracted from our real life and cultures, conforming to general moral requests of the masses. Abidance by the norms of socialist core values means a kind of free self-discipline, namely observing our own reason rather than others' force. Thus, the moral excellence of socialist core values is embodied in that individuals realize interpersonal harmony and constantly improve their inherence through different internal free self-discipline practices.

Secondly, socialist core values, as a political ideology, needs the participation of aesthetics. Though Kant put forward the disinterestedness of aesthetics, he didn't deny the utilitarian effect of aesthetics on subjects. Beauty, as a value, permeates into every aspect of life, and impacts politics, economy, and culture.

On one hand, political ideology itself contains aesthetic factors more or less, and these factors provide certain spiritual motivation to the successful practice of political ideology. In the view of Eagleton, aesthetics, body and political leadership are intertwined. That's to say, the state interferes people's "body" and daily social life via aesthetic system, with a view to bring the most effective political leadership model into full play. It is the same with socialist core values. If the socialist core values itself is not beautiful, it will not attract the masses. On the other hand, political ideology needs to be evaluated from the perspective of aesthetic value or aesthetics. Beauty, objective or subjective or both, contains reasonable factors. Undoubtedly, if these factors are used to examine the political ideology, the unreasonable will be restored or corrected. From the aspect of aesthetic evaluation on the whole, socialist core values, as value principle, value standard and value ideal, reflects the unification of truth, goodness and beauty, conforming to the development law of the history of mankind.

Thirdly, to make socialist core values be internalized as a faith by people, aesthetic education is indispensable. Presently, the development and practice of socialist core values are actively promoted with an aim to make socialist core values be internalized and embodied effectively. Only in this way, the core values can be put into full play. How to make socialist core values be internalized is both a theoretical problem and a practical problem. Education shoulders the task of solving theoretical problem and practical problem.

\section{Analysis of Aesthetic Dimension of Socialist Core Values from A Three-dimensional Perspective}

\section{Aesthetic Theory Dimension of Socialist Core Values}

Theoretically, the correlation between aesthetics and politics and ethics is an important research direction of aesthetics. Aesthetic or aestheticization interpretation of socialist core values, theoretically, relates to theories on aesthetic system and values relating to socialist core values; in terms of experience, is empirical to a certain extent. Hence, the inner requirements of its theory have enriched and developed the Marxist value theory, and also are important contents of and the guarantee for the persistence in and development of the socialism with Chinese characteristics. 
Realistically, the aesthetic interpretation of socialist core values has pushed the socialist core value system to develop to be popular, unifying the social ideological trend into truth, goodness and beauty, and giving overall consideration to and organically combining scientificity with artistry, and entirety with individual so as to cope with the shock and challenge of western values. The aesthetic dimension of socialist core values relates to the process of improvement and development of such theoretical systems of politics, aesthetics, philosophy and ethics, and also is a result of constant accumulation, extraction and sublimation based on practice, reflecting a profound historical, logical and practical foundation. That the state, society and citizens are associated with each other makes that their demands for socialist core values mutually cross, namely the embodiment of socialist core values mediating the conflicts between social development and individual aesthetic desire via power and ideology to seek its legality and stability among different cultures. Socialist core values holds an important strategic position in the ideological strategy of the state. Ideology itself contains aesthetic factors more or less. These factors act as a most effective political leadership model in the aesthetic system construction of the state as a kind of spiritual motivation. Though Kant considered aesthetics to be disinterested, beauty, as a value, itself automatically permeates into various aspects of our life such as politics, economy, and culture, and has certain influence. Aesthetic activities are not only free, but of "common sense". Such common sense makes aesthetics as a means of constructing social community link aesthetics with ideology, and aesthetic judgment with political judgment.

\section{Individual Aesthetic Dimension of Socialist Core Values}

Concerning aesthetic breakthrough of socialist core values, the subject must be stressed, and the point must be hit, mobilizing and motivating Party members, cadres workers, farmers, the intelligentsia, staff of new economic and social organizations, and the public figures especially the celebrities in all circles to form a strong force for the development and practice of socialist core values.

The subject of socialist core values development should consists of communication subject and reception subject. The communication subject itself must be an admirable model so as to be competent for the task of training others. (1) The communicator of socialist core values should have a good personal image, which is reflected by external gestures and languages and internal cultural quality, noble moral sentiments and personality charm. The communicator must have a good command of theoretical knowledge of multiple disciplines, be capable of bringing the knowledge together and understanding it thoroughly, have an insight into real life and a solid literature and art foundation, be able to accurately comprehend the psychological characteristics of the masses, and have a strong interpersonal communication ability. The reception subject refers to "not only the human being with autonomy, but also concrete and realistic person living in certain social and historical form and working on certain social practice. The realistic circumstances, subject consciousness, and subject's ability of reception subject directly impact his demands of reception, receptivity, and reception effect." The values, political stand, aesthetic demand, and life demands of reception subject will influence his aesthetic reception. The masses will reject any image they don't welcome or recognize, and thus no effect of image will be achieved. In view of this, we are supposed to stand in the masses' position and listen to the masses to understand their likes and dislikes.

\section{Aesthetic Practice Dimension of Socialist Core Values}

To develop and practice socialist core values, from the aspect of state, efforts must be made to present the aesthetic value in line with the "state's will"; from the aspect of society, efforts must be made to determine the aesthetic value guidance of social development; from the aspect of individual, efforts must be made to construct aesthetic bottomline ethics of the folk society.

The top priority for realizing aesthetic practice of socialist core values is to create a practice environment for socialist core values. Environment refers to natural, social and cultural conditions that human depend on to carry out their principal activities, which unconsciously influences and edifies human in a unique way. In the process of perfecting and improving the environment of socialist core values, the characteristics and time features of socialism were built by multiple means 
and forms to infiltrate contextual and artistic factors into specific values, code of ethics, and code of conduct, the space of the cultivation environment was made full use of to create a real visual and vivid emotional experience environment, and a social practice environment of aesthetic knowledge, wisdom and ability was obtained to form an atmosphere of "classrooms can be found everywhere, and education is accessible anytime", realize the effect of "moistening things silently", and let the masses feel the truth and life of socialist core values, and recognize, accept and practice in the atmosphere and state of beauty.

\section{Essential Embodiment of "Holding Goodness and Truth through Beauty" and Practical Function of "Enlightening Truth and Goodness through Beauty"}

"Holding goodness and truth through beauty" refers to that beauty contains truth and goodness, beauty is based on truth and goodness, and beauty is the concrete embodiment of practice freedom of unification of conformity with law and conformity with purpose, of utilitarian and disinterestedness, and of individuality and groupment. This is provided by the essence of value of beauty. According to this viewpoint, Chinese contemporary aesthetics at the primary stage of socialism should be under the guidance of socialist core values to show the dialectical unity of truth, goodness and beauty-holding goodness and truth through beauty, manifesting socialist core values by means of aesthetic image and aesthetic value. There is no exception for natural beauty, social beauty and artistic beauty. Especially, it is the case for artistic beauty. Art unifies truth, goodness and beauty. The social functions of realization and education of art also should and must be put into play via aesthetic function of art. Art is supposed to realize a dialectical unity of truth and goodness even though it is employed to reveal the ugly or evil in real life, namely realizing the dialectical unity of beauty of art in contents and in form. Only based on "holding goodness and truth through beauty", the special function of "enlightening truth and goodness through beauty" can be realized, and the power and far-reaching effect of aesthetic education and artistic education can be achieved. Beauty can help enlighten truth and goodness, and guides the value of truth and goodness in an eyeable way. Therefore, socialist core values exercises a unique function of "enlightening truth and goodness through beauty" of aesthetics.

All in all, only by considering the nature and function of beauty from the perspective of the dialectical unity in the value system of truth, goodness and beauty, we can truly understand the internal essence of "holding goodness and truth through beauty" and the aesthetic function and aesthetic education function of "enlightening truth and goodness through beauty", to construct modern aesthetics with Chinese characteristics under the guidance of Marxism, based on Chinese traditional aesthetic ideology and referring to western aesthetics with socialist core values as the value orientation and development direction, regard socialist core values as a value ideal, and believe more firmly in the inevitability of realizing socialist core value ideal via aesthetic education.

\section{References}

[1] Li Ying. A Study on Ideological and Political Education Reception from the Perspective of Philosophical Hermeneutics, Hangzhou: Zhejiang University Press, 2013: 64 - 65.

[2] Aesthetic Connotation of Socialist Core Values, Li Fengling, Journal of Beijing Normal University (Social Science Edition), Issue 5, 2015.

[3] Value Nature of Beauty and Core Value, Zhang Yuneng1, Zhang Gong 2, Hundred Schools in Arts, Issue 3, 2015. 